Iranian (Iranica) Journal of Energy \& Environment
Journal Homepage: www.ijee.net
IJEE an official peer review journal of Babol Noshirvani University of Technology, ISSN:2079-2115

Technical Note

\title{
Reuse of Reverse Osmosis Membranes - Case Study: Tajoura Reverse Osmosis Desalination Plant
}

\author{
B. Brika ${ }^{*}$, A. A. Omran², N. Greesh ${ }^{1}$, A. Abutartour ${ }^{3}$ \\ ${ }^{1}$ Advanced Laboratory of Chemical Analysis, Authority of Natural Science Research and Technology, Tripoli, Libya \\ ${ }^{2}$ Water Desalination Research Section, Water Desalination Department, Tajoura Nuclear Research Center (TNRC), Tripoli, Libya \\ ${ }^{3}$ Beijing University of Chemical Technology, Beijing, China
}

\section{$P A P E R \quad I N F O$}

\section{Paper history:}

Received 16 September 2019

Accepted in revised form 24 November 2019

\section{Keywords:}

Desalination Technology

Reverse Osmosis

Membrane Material

Environment

\section{$A \begin{array}{llllllllllll} & B & T & R & A & C & T\end{array}$}

Libya is currently experiencing a major challenge in water supply due to reduction in the groundwater, especially around the coastal region. This problem is likely to create challenges for drinking water supply and the agricultural sector. Environmental desalination technology and wastewater treatments could provide a solution to the problem. In Libya, there are approximately 21 operating desalination plants, with a total capacity of $525,680 \mathrm{~m}^{3} / \mathrm{d}$. The Tajoura desalination plant is one of the oldest reverse osmosis (RO) desalination plants established on the west coast of Liby. It has been under operation for three decades with no significant attention to these systems. Membranes used in Tajoura plant were not regularly checked or replaced on time. This paper reviews the history of membranes used in Tajoura plant since its installation, specifically storage methods and the number of damaged membranes. Finally, alternative options for reuse of used membranes are proposed. It was found that a couple of reuse options are possible for some membrane elements. Converting the fiberglass of the outer casing into small pieces or powder for other production is highly recommend, while polypropylene spacers provide good opportunities for domestic and agricultural applications.

doi: $10.5829 /$ ijee.2019.10.04.11

\section{INTRODUCTION}

Libya has an increasing demand for drinking water and irrigation due to increasing population. The Libyan population rapidly increased from less than one million in 1955 to 6 million in 2005 and is expected to reach more than 12 million by the year 2025 [1]. Inadequate potable water remains a major concern in Libya today, in the small towns as well as big cities. The country has an annual average rainfall of less than $100 \mathrm{~mm}$ and its groundwater is being overexploited, especially in the coastal regions. Groundwater is the main water source in Libya, followed by the man-made river project (MMRP). Desalination using membrane technology is noticeably becoming common worldwide, although Libya is still not making serious use of such technology. Due to the decreased amount of fresh groundwater and the current unstable conditions of the MMRP, there is serious consideration amongst the Libyan water authorities to turn to the desalination sector. Desalination plants are expected to be installed in most of the Libyan coastal cities in the next few years. The Libyan government, represented by the Libyan water authorities, has made the decision to build new reverse osmosis desalination plants in Tripoli. One of these new plants is to be the largest of its kind in the region with a capacity of $500,000 \mathrm{~m}^{3} /$ day. The location of this large new plant is still not confirmed, although it will possibly be located near the old desalination plant in the city of Tajoura [2].

Safe and clean disposal of used membranes in reverse osmosis desalination plants should be taken into account while constructing new desalination plants. Environmental restrictions also have to be imposed.

At present, there is not much research in the field of recycling or reuse of membranes; therefore, it is very important to investigate options to eliminate the negative impacts of reverse osmosis (RO) used membranes and to look for new options to reuse membranes.

\section{Tajoura reverse osmosis desalination plant}

The Tajoura desalination plant is considered to be the first and the largest desalination plant in Libya operating with reverse osmosis technique. The plant was designed with a capacity of 
$10,000 \mathrm{~m}^{3} /$ day. In 1984 , the Tajoura desalination plant first started to operate at half its capacity $\left(5000 \mathrm{~m}^{3} /\right.$ day $)$, due to the lack of consumers. The Tajoura reverse osmosis (RO) desalination plant was designed to be operated in two stages [3]: in the first stage, membrane modules with a 6 inch diameter were used, and sea water was used as raw water to be desalinated, while in the second stage, membrane modules with an 8 inch diameter were used. Water produced during the first stage was used as raw water in the second stage. Ten years after the foirst operation of the Tajoura RO plant, new membranes ( 8 inches in diameter) were enhanced in order to desalinate sea water directly in only one stage. In this stage, 540 membrane modules were used in two rows.

Membranes in the Tajoura RO plant used to be installed every five to seven years. The estimated number of membrane modules in each period is 594 for each row (total rows $=4$ ). This number clearly shows that the total number of membrane modules changed in the first stage (6 inches in diameter) reached to 1188 , while in the second stage ( 8 inches in diameter) 252 membrane modules were replaced by new ones. Figure 1 shows membrane modules as currently used in the Tajoura desalination plant. The lifespan of the Tajoura RO desalination plant is about to reach its end; therefore, urgent action is required regarding the disposal of most of the plant's systems (intake, high pressure pumps, membranes, and all the related equipment).

The aims of this paper are: (i) to critically review the current disposal of the used membranes; (ii) to discuss the possibilities of different reuse options. The authors, therefore, intend making a proposal that includes a number of options for making use of the old membranes in other ways.

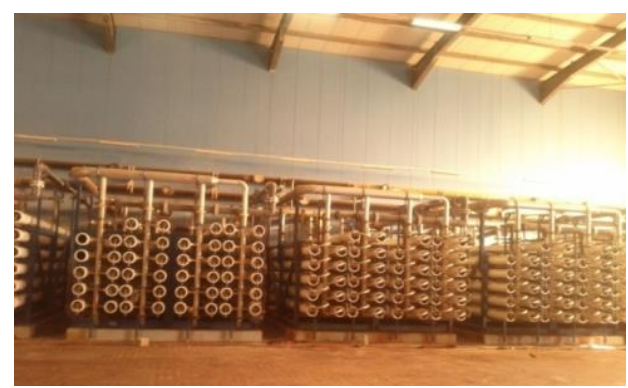

Figure 1. Spiral wound membrane modules in the Tajoura desalination plant
History of membranes used in Tajoura desalination plant The membranes used in the Tajoura plant are replaced after some time (usually over 5 years). The number of membranes already used and replaced in the Tajoura plant from 1984 till now might reach some 8000 units. Types of membranes and some of their specifications are presented in Table 1.

It has to be mentioned that recovery for membranes of 6 inch in the first stage reached $30-33 \%$, while for membranes of 8 inch in the second stage operated with a recovery of approximately $75 \%$. Recovery for membranes of 8 inch during period from 2000-2013 reached 98\%.Data presented in Table1 summaries the membranes used in the Tajoura desalination plant. The total number of membranes that have been used is 8136 units, divided into two stages (6372 units in the first stage, and 1764 units in the second stage). Most of the membranes were $20 \mathrm{~cm}$ in diameter (8") and $1 \mathrm{~m}$ long. Consequently, a stock of used membranes has piled up over the years. These units can no longer be used for seawater desalination because they have lost their original properties due to fouling, scaling, etc. and might have an environmental impact when disposed. Alternatively, it is suggested that these old membranes may have remaining value if reused in different applications [4].

The next section clearly describes the conditions of the used membranes in the Tajoura plant.

\section{Used membranes in the Tajoura desalination plant}

Currently, used membranes in the Tajoura RO desalination plant are generally disposed of via landfill. Due to the disposal process of used membranes, these may take long time to reach their final place, which is mostly a land area filled with trash.

When the lifespan of the membranes is reached, the quality control department at Tajoura plant take the right and safe action by doing all the necessary analysis regarding the produced desalinated water. If the results of the analysis lie outside Libyan standards for drinking water, the decision makers in the plant together with the Tajoura Nuclear Research Center have to seriously consider removing the used membranes and replacing them with new ones. The supervisors of the plant units will take the old membranes and place them in containers specifically brought for this purpose, as can be seen in Figure 2 .

TABLE 1. Membranes used in the Tajoura RO desalination plant

\begin{tabular}{|c|c|c|c|c|c|c|c|c|c|c|}
\hline \multirow{3}{*}{ Period } & \multirow{3}{*}{$\begin{array}{c}\text { Membrane } \\
\text { diameter }\end{array}$} & \multicolumn{6}{|c|}{ Number of units (elements) } & & & \multirow{3}{*}{$\begin{array}{c}\text { Raw } \\
\text { water } \\
\text { source }\end{array}$} \\
\hline & & \multicolumn{4}{|c|}{ First stage } & \multicolumn{2}{|c|}{ Second stage } & \multicolumn{2}{|c|}{ Membrane model } & \\
\hline & & R405 & R406 & R407 & R408 & $\mathbf{R 4 1 0}$ & R411 & First stage & Second stage & \\
\hline 1984-1989 & $6 "+8 "$ & 594 & 594 & 594 & 594 & 252 & 252 & TFC 1501 & TFC 8600 & $\begin{array}{l}\text { S.W } W^{*}- \\
\text { Br. } W^{* *}\end{array}$ \\
\hline 1990-1991 & $6 "+8 "$ & - & - & 594 & 594 & 252 & - & TFC 1501 & TFC 8600 & S.W-Br.W \\
\hline $1992-2000$ & $6 "+8 "$ & 594 & 594 & - & - & 252 & - & TFC 1501 & TFC 8600 & S.W-Br.W \\
\hline $2000-2005$ & $8 "$ & - & - & 270 & 270 & - & - & TFC 282255-360 & - & S.W \\
\hline $2005-2013$ & $8^{\prime \prime}$ & 270 & 270 & 270 & 270 & - & - & TFC 282255-360 & - & S.W \\
\hline
\end{tabular}

** Br.W: Brackish water 


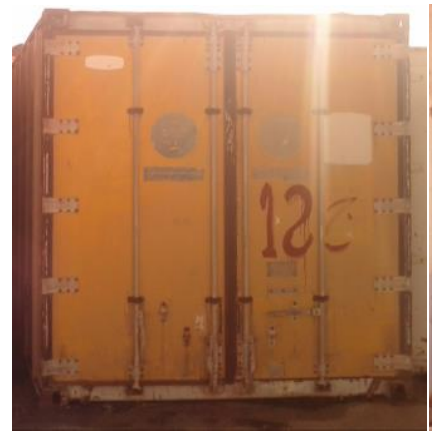

(a)

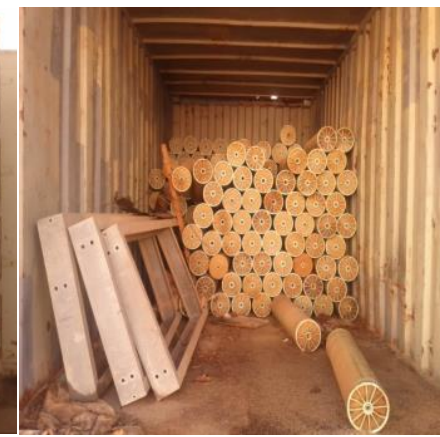

(b)
Figure 2. The container (a) and used membranes installed in a container (b)

When the process of loading the used membranes is completed, the container is locked for an unknown period, as there is currently no safe way to discharge these old membranes. Workers and operators at the Tajoura plant confirm that the plant construction company have not made any recommendations regarding how to discharge old membranes safely or repurpose them. Figure 3 show some of the used membrane cells. It can be clearly seen that the used membrane cells were placed above each other randomly. It can also be observed that the membrane cells are contaminated with deposits that could have a negative impact on the human body as well as the environment.

\section{METHODOLOGY}

This study was mainly conducted to assist the people responsible for the plant and the operators to understand the potential environmental impacts of long-term storage of the used membranes better. Secondly, it aimed to find the best way to repurpose these old units or eliminate them in a more proper and sustainable way.

The RO membrane that was examined consists of two membrane sheets glued together and spirally wound around a perforated central tube through which the permeate (product water) exits the membrane element. The first membrane sheet, is made of thin-film composite polyamide material and has microscopic pores. This membrane sheet is supported by a second, thicker membrane sheet, which is made of higher-porosity polysulfone material (PSf). In addition, the membrane element structure contains a

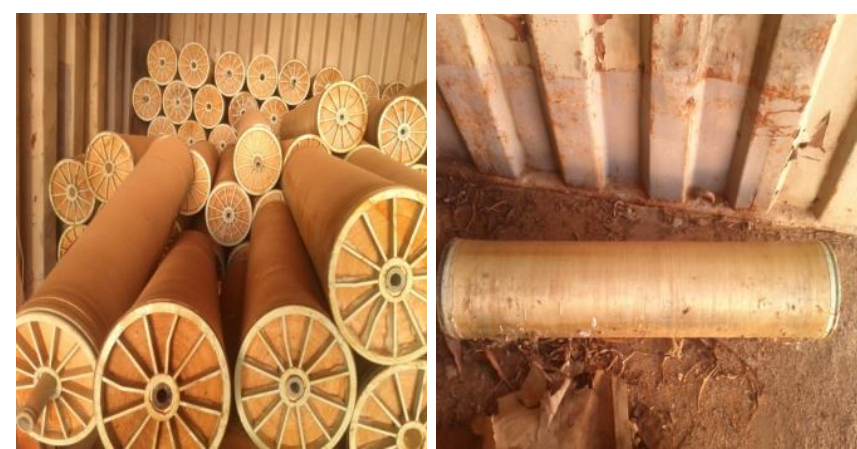

Figure 3. Used membrane cells feed spacer, made of polypropylene (PP), a permeate spacer made of polyester, a permeate tube and end-caps made of acrylonitrile butadiene styrene (ABS), an outer casing made of fiberglass and the glued parts containing proprietary epoxy-like components. Having named the materials of each membrane component, the authors believe that the chemical analysis can further help to suggest options to repurpose each part of the old membrane in a way that would be acceptable for the environment.

\section{Experimental}

During the development of this study, two experimental analyses were done to identify the chemical composition and the thermal stability of the main parts of the membrane. The membrane components were separated and cut into small samples and sent to the laboratory. Figure 4 shows the image of the membrane component samples analyzed in this study.

The membrane components shown in Figure 4 were analyzed by thermogravimetric (TGA) analysis and some of them, due to some difficulties, were characterized by Fourier transform infrared (FTIR).

\section{RESULTS AND DISCUSSION}

\section{Combustion and carbonisation}

Thermogravimetric analysis (TGA) is a thermal analysis technique that measures the weight, and hence the mass, of a sample as a function of temperature. TGA allows us to detect changes in the mass of a sample (gain or loss), evaluate stepwise changes in mass (usually as a percentage of the initial sample mass) and determine temperatures that characterize a step in the mass loss or mass gain curve. TGA of membrane component samples was carried out using a HCT-5022 thermo-analyzer (Beijing Hengjun Instrument Company, China). Samples of 10-15 mg were degraded under nitrogen atmosphere (flow rate $50 \mathrm{ml} / \mathrm{min}$ ) at a heating rate of $10^{\circ} \mathrm{C} / \mathrm{min}$

Figure 5 shows the results of the thermogravimeric analyses of the membrane components. The figure shows that sample number 2 (glues) is the least thermally stable component, showing almost complete degradation around $480{ }^{\circ} \mathrm{C}$, while sample number 5 (feed spacer) is the second least thermally stable component as it is completely combusted at $520^{\circ} \mathrm{C}$, followed by the permeate spacer (4) and permeate tube (6). The remaining membrane components

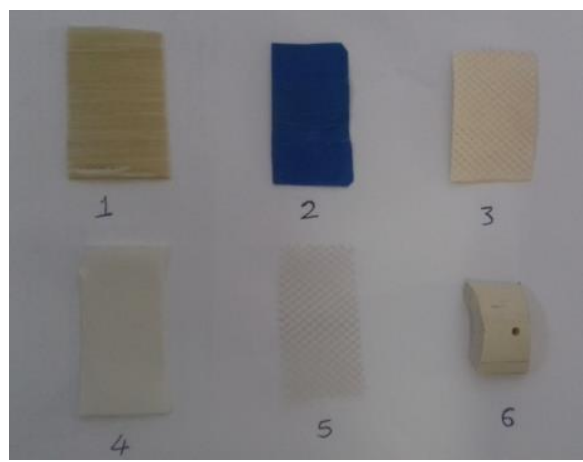

Figure 4. Different membrane components that were tested in this study. From left to right: outer casing (1), glues (2), membrane sheet (3), permeate spacer (4), feed spacer (5), permeate tube (6) 


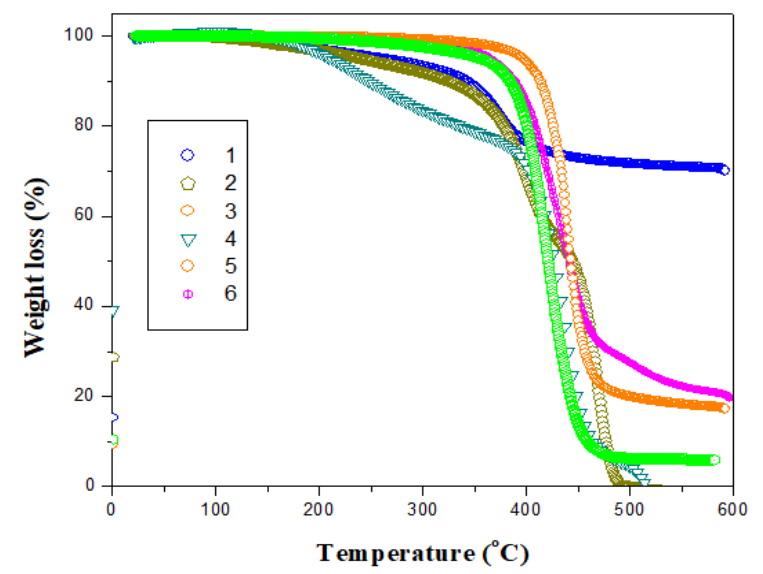

Figure 5. Thermogravimetric analysis (TGA) of membrane element components

including outer casing (1) and membrane sheet (3) are much more thermally stable as their curves decrease slowly towards a zero weight. In the case of the outer casing, which comprised mainly fiberglass, an inorganic residue of about 67 wt\% remains after TGA combustion.

Based on the thermogravimetric analysis, it is possible to thermally degrade the polymer components to carbon using thermal treatments [5]. Except for the fiberglass outer casing, all membrane element components are suitable for combustion and carbonisation treatment to convert the polymer components into an energy source [6].

\section{Chemical composition}

From the polymer recycling point of view, it is an important step to identify the raw material of each component of the membrane. The authors believe that it might be possible to suggest more recycling options of each membrane component individually. Based on this concept the Fourier transform infrared spectroscopic analysis (FTIR) was the only available technique to be used for identifying the polymer composition of the major membrane components.

FTIR spectra were recorded in the range $4000-400 \mathrm{~cm}^{-1}$ with $2 \mathrm{~cm}^{-1}$ resolution on a Bruker Vector-22 Fourier transform spectrometer using the $\mathrm{KBr}$ pellet technique (1.0 $\mathrm{mg}$ of sample in $100.0 \mathrm{mg}$ of $\mathrm{KBr}$ ). The FT-IR spectra analysis confirms that the feed spacer is comprised of polypropylene and the permeate spacer is made of polyester. The permeate tube and end caps are comprised of an amorphous material such as acrylonitrile butadiene styrene (ABS). The FT-IR spectroscopic analysis further showed that the outer casing is clearly made of fiberglass. The detailed polymer composition of the membrane components are illustrated on Table 2.

\section{REUSE AND RECYCLING OPTIONS}

Generally, the disposal of waste plastics has not yet become a major environmental problem in Libya. Additionally, there are few government regulations concerning waste disposal management. As a result, there are a limited numbers of small companies that deal with plastic waste collection in the city of Tajoura where the desalination plant is located. However,
TABLE 2. Composition of typical membrane components as it is exacted from FTIR analysis

\begin{tabular}{lc}
\hline Membrane component & Composition \\
\hline Outer casing & Fiberglass \\
Feed spacer & Poly propylene (PP) \\
Permeate spacer & Polyester \\
$\begin{array}{l}\text { Membrane sheet } \\
\text { thin film composite) }\end{array}$ & Aromatic polyamide \\
Permeate tube/end caps & Microporous polysulfone (PSf) \\
Glues & Acrylonitrile butadiene styrene (ABS) \\
Rubber o-rings & Epoxy resin \\
\hline
\end{tabular}

few of them engage with the plastic waste recycling process. Local companies collect plastic waste, compact them and sell them to other local companies/factories or export them internationally for further industrial processing and manufacturing.

In order to evaluate the potential value of recycled polymer materials membrane components were separated and taken to one of the local companies. Membrane components were observed and examined carefully by the plastic waste recycling company's management team, and the following comment was made:

Currently, and due to the lack of investment, advanced equipment and expert personnel, the only membrane elements that could be recycled are the ones comprising a single polymer component such as the outer casing, feed spacer and permeate spacer. Nevertheless, the local companies might not be able to recycle these components due to the lack of suitable separation technology equipment for such RO membrane cells.

Regarding alternative suggestions for the disposal and reuse of used RO membrane elements, the authors suggest the following:

- Permeate tube: an alternative reuse option is to connect a number of permeate tubes and use for irrigation (Figure 6)

- Feed/permeate spacers for agricultural and domestic applications

- Feed spacer to prevent mosquitoes attack via house's windows (Figure 7)

- Permeate spacer as geotextile as reported in previous studies [6-9].

- Feed spacer is considered to be a single-polymer plastic that is clean and homogenous. Therefore, it can also be directly recycled (mechanical recycling) and used as feed stock for the production of new products such as containers and packaging. This suggestion is in accordance with those stated in some previous investigations [10].

- Mechanical grinding can be done for some old RO membrane elements such as the outer casing, which is made of fiberglass. Grinding is the most obvious processing method used for recycling fiberglass. It leads to reducing material to small pieces or powder to be reused in other products. Grinding of fiberglass could provide a filler material or aggregate that could be used in concrete. Fiberglass powder could be used to make thermoforming molds or other structures. 


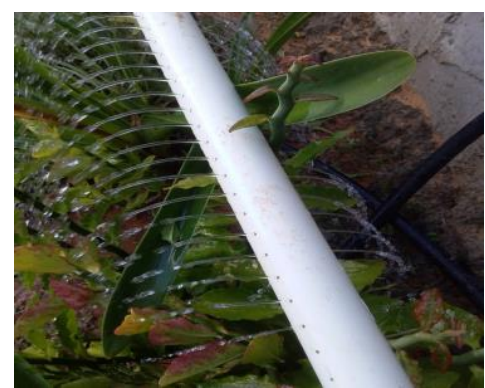

Figure 6. Permeate tube for irrigation

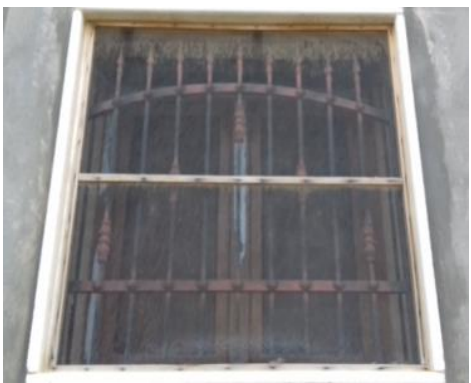

Figure 7. Window's protection from Mosquitoes attack

- RO membrane elements which comprise mixed plastic materials such as the membrane sheet can be used as an energy source. Gasification and pyrolysis are preferable processes to incineration because they produce fewer emissions.

\section{CONCLUSIONS AND RECOMMENDATIONS}

This paper provided an overview of the old RO membranes in the Tajoura desalination plant. Since landfills, which are considered the only disposal route for old membranes, are facing capacity issues, alternative disposal or reuse options have become necessary.

As it is considered to be the first serious piece of work that concerns the reuse of old seawater RO membranes from the Tajoura desalination plant, the authors highly recommend that further developments and additional work be done in this area at local and regional levels.

Based on the findings of this work and other related investigations, the authorized governmental authorities should make a huge effort to find potential international users for expired membranes. In this regard, it is expected that this point be made clear in contracts when establishing new desalination plants. The local authorities and decision makers should take the initiative to invest partly or entirely in new, friendly desalination technology such as "the remembrane project".

\section{REFERENCES}

1. National Authority for Statistical Information and Documentation (NASID), 2006. Personal Communication by the Author. Tripoli, Libya.

2. Brika, B., 2016. Environmental implications of Tajoura reverse osmosis desalination plant. Desalination and Water Treatment, 57(46) pp.21712-21720.

3. Brika, B., Omran, A.A. and Dia Addien, O., 2016. Chemical elements of brine discharge from operational Tajoura reverse osmosis desalination plant. Desalination and Water Treatment, 57(12), pp.5345-5349.

4. Rodriguez, J.J., Jiménez, V., Trujillo, O. and Veza, J., 2002. Reuse of reverse osmosis membranes in advanced wastewater treatment. Desalination, 150(3), pp.219-225.

5. Dollimore, D. and Heal, G.R., 1967. The degradation of selected polymers to carbons in an inert atmosphere. Carbon, 5(1), pp.65-72.

6. Prince, C., Cran, M., Le-Clech, P., Uwe-Hoehn, K. and Duke, M., 2011. Reuse and recycling of used desalination membranes. In proceedings of OzWater'11, Adelaide, Australia, pp.1-8.

7. Piernavieja, G., Veza, J.M. and Padrón, J.M., 2001. Experience in desalination training and know-how in the Canary Islands. Desalination, 141(2), pp.205-208.

8. Mohamedou, E.O., Suarez, D.P., Vince, F., Jaouen, P. and Pontie, M., 2010. New lives for old reverse osmosis (RO) membranes. Desalination, 253(1-3), pp.62-70.

9. Pontié, M., 2015. Old RO membranes: solutions for reuse. Desalination and Water Treatment, 53(6), pp.1492-1498.

10. Lawler, W., Bradford-Hartke, Z., Cran, M.J., Duke, M., Leslie, G., Ladewig, B.P. and Le-Clech, P., 2012. Towards new opportunities for reuse, recycling and disposal of used reverse osmosis membranes. Desalination, 299, pp.103-112.

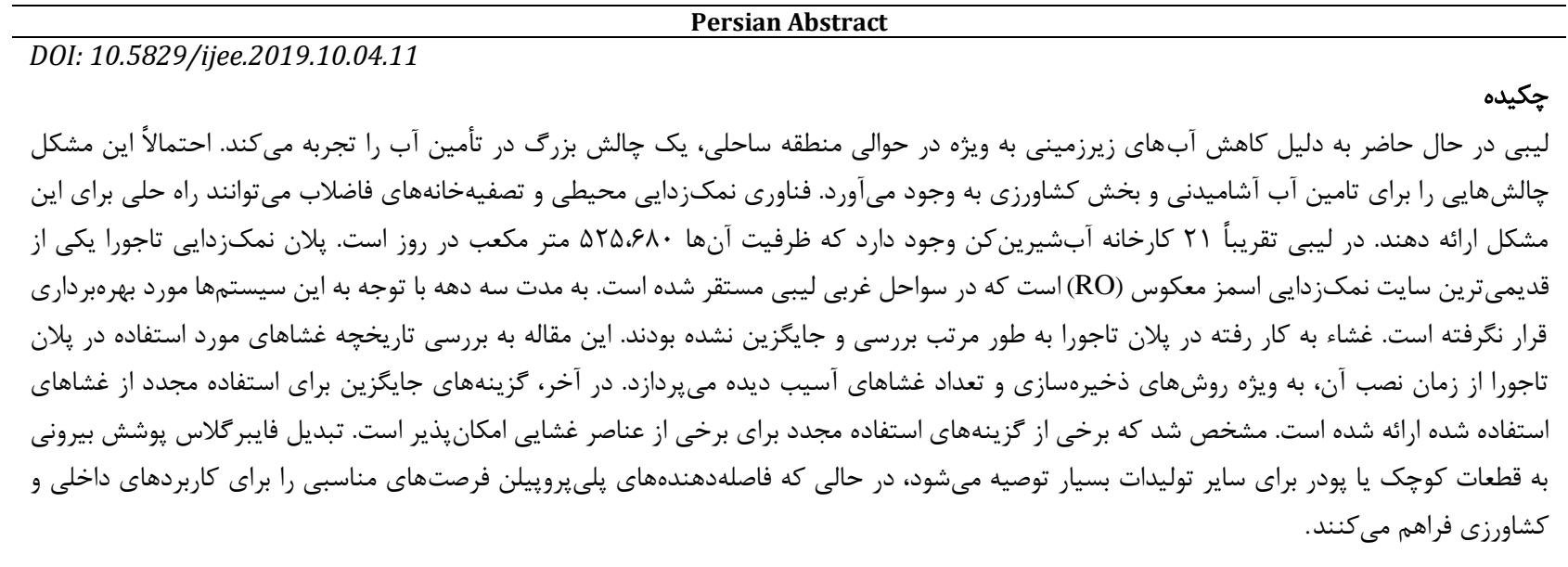

